九州大学学術情報リポジトリ

Kyushu University Institutional Repository

\title{
Multiscale Modeling Study of the Adsorption of CO_2 Using Different Capture Materials
}

Abouelella, Dina M.

Chemical Engineering Department, Cairo University

Fateen, Se if-Eddeen K.

Chemical Engineering Department, Cairo University | Environmental Engineering Program, Zewail City of Science \&Technology

Fouad, Mai M. K.

Chemical Engineering Department, Cairo University

https://doi.org/10.5109/1929729

出版情報: Evergreen. 5 (1)，pp.43-51，2018-03. Green Asia Education Center バージョン:

権利関係 : 


\title{
Multiscale Modeling Study of the Adsorption of $\mathrm{CO}_{2}$ Using Different Capture Materials
}

\author{
Dina M. Abouelella ${ }^{1, *}$, Seif-Eddeen K. Fateen ${ }^{1,2}$, Mai M. K. Fouad ${ }^{1}$ \\ ${ }^{1}$ Chemical Engineering Department, Cairo University, Egypt \\ ${ }^{2}$ Environmental Engineering Program, Zewail City of Science \&Technology, Egypt \\ *Author to whom correspondence should be addressed, \\ E-mail:dina.abouelella1@gmail.com
}

(Received January 10, 2018; accepted March 9, 2018).

\begin{abstract}
The removal of $\mathrm{CO}_{2}$ from flue gases is one of the potential mitigation measures to address the climate change problem. To that end, adsorption is a promising technology that is currently being developed. The scope of the present work is to study the mass transfer profiles at multiscale levels for adsorption $\mathrm{CO}_{2}$ and the effects of both macropores and micropores for different sorbents. A one-dimensional multi-scale model has been developed to produce breakthrough curves for adsorption $\mathrm{CO}_{2}$ from gas streams using different capture material. The developed model matched literature experimental data reasonably well for three different sorbents at different operating conditions.
\end{abstract}

Keywords: Adsorption, breakthrough curve, modeling, $\mathrm{CO}_{2}$ Capture, CFD

\section{Introduction}

Carbon dioxide $\left(\mathrm{CO}_{2}\right)$ has become a focus of scientific attention as its emissions is considered the main reason for both the climate change and the global warming effect. ${ }^{1,2}$ The earth's atmosphere consists of nitrogen $\left(\mathrm{N}_{2}\right)$, oxygen $\left(\mathrm{O}_{2}\right)$ and other gases with approximate percent of 78,21 , and $1 \%$, respectively, where other gases are mainly water vapor and carbon dioxide. The atmospheric concentration of greenhouse gases (GHG), mainly $\mathrm{CO}_{2}$, has increased gradually in the last century. This increase resulted in an increase of the earth temperature due to $\mathrm{CO}_{2}$ and other GHGs, which make a partial blanket for thermal radiation of the earth. The main sources of $\mathrm{CO}_{2}$ emissions are the flue gas of power plants and automobile emissions. ${ }^{3)}$ Coalfired power plants supply $41 \%$ of the world electricity and contribute $42 \%$ of $\mathrm{CO}_{2}$ emissions. Coal is one the cheapest sources of electricity which is considered the one of main resources of $\mathrm{CO}_{2}$ emissions. Thus, limiting of $\mathrm{CO}_{2}$ emissions from coal-fired plants could be an economically-viable option, which may reduce global atmospheric concentrations of greenhouse gases. The iron and steel industries accounts $10-15 \%$ of total industrial energy consumption. The estimated $\mathrm{CO}_{2}$ emissions worldwide were $35,600 \mathrm{MtCO}_{2}$ in 2015.,45)

During the period from 1750 to 2011, the concentration of greenhouse gases has increased from 280 to $385 \mathrm{ppm}^{6}$. The Intergovernmental Panel on Climate Change (IPCC) stated in 2007 that the total emissions of anthropogenic greenhouse gases $\left(\mathrm{CO}_{2}\right.$, methane $\left(\mathrm{CH}_{4}\right)$ and nitrous oxide (NOx) increased by 70\% between 1970 and 2004 due to human activities. While the European Union (EU) emphasized the necessity to reduce $\mathrm{CO}_{2}$ emissions in developed countries by $30 \%$ in 2020 compared to 1990 levels. Also, the EU decided to achieve a $20 \%$ reduction of its emissions of greenhouse gases in 2020 compared to 1990 level. ${ }^{7)}$ The average concentration of $\mathrm{CO}_{2}$ is estimated by IPCC to be 570 in $2100 .{ }^{8} \mathrm{CO}_{2}$ Capture is considered the most suitable method that can be applied for large point sources such as fossil fuel power plants, fuel processing plants and other large industries. The aim of carbon capture is the production of a concentrated stream that can be readily transported to carbon dioxide storage site. ${ }^{7,8)}$

The modeling of the adsorption process is an important step in understanding the underlying transport phenomena that occur within the adsorbers. This understanding that is developed by modeling aids the design and optimization of the adsorption technology. Thus, various researchers have developed models for $\mathrm{CO}_{2}$ adsorption. SernaGuerrero et al. ${ }^{9)}$ developed one dimensional (1D) model to simulate a fixed bed packed column to simulate the adsorption $\mathrm{CO}_{2}$ on amine functionalized mesoporous silica sorbent. The model was capable of describing the uptake of $\mathrm{CO}_{2}$ in the temperature range of $25-75^{\circ} \mathrm{C}$, with a standard deviation of less than $3.5 \%$. The developed model had a small discrepancy towards the amount of uptake $\mathrm{CO}_{2}$ that were mentioned to be a result of the assumptions used to solve the fixed bed model. Shafeeyan et al. applied the similar concept of Serna-Guerrero to model a capture process of $\mathrm{CO}_{2}$ using COMSOL software that matched the experiments for adsorption of $\mathrm{CO}_{2}$ on the ammonia modified activated carbons. ${ }^{10)}$ Pseudo firstorder, pseudo second-order and Avrami kinetic models were used to study the adsorption process of $\mathrm{CO}_{2}$ in the temperature range $30-60^{\circ} \mathrm{C}$. The Avrami model provided 
the best fitting for kinetics data while the pseudo secondorder models gave the highest deviation for the simulated results. Only the effect of bed porosity was taking into account during simulating proposed model. Qasim et al. described capture $\mathrm{CO}_{2}$ by nanoporous activated carbon from $\mathrm{CO}_{2} / \mathrm{CH}_{4}$ gas mixture using one dimensional model developed by ANSYS FLUENT Software. ${ }^{11)}$ Although the bed void fraction was only considered during the breakthrough curve simulation, the developed model validated the experimental data with total error of $4 \%$.

Ding and Alpay reported the modeling of a fixed packed bed to simulate the adsorption of $\mathrm{CO}_{2}$ on the potassium promoted hydrotalcite adsorbent. ${ }^{12)}$ The flow in the packed bed was modeled as axially dispersed plug flow without radial concentration and temperature gradient. The Linear Driving Force Model (LDF) based on the pore diffusion model, that had the ability to account the non-linearity of the isotherm, was reported to provide a good simulation for the adsorption and desorption experimental data. The model took in its account the effect of both pellet and bed porosities. The pellet mass balance included two important parameters: $\mathrm{D}_{\mathrm{p}}$, which accounted the effect molecular and Knudsen diffusivities parameter, and $D_{s}$, which accounted for the effect of surface diffusivity. Bollini et al. applied a simple shell mass balance inside a spherical adsorption particle to model adsorption process of $\mathrm{CO}_{2}$, controlled by diffusion, by 3aminopropylsilyl-functionalized SBA-15 silica sorbents at three different amine loadings and $13 \mathrm{X}$ zeolite. ${ }^{13)}$ The results showed that the commercial zeolite $13 \mathrm{X}$ had lower $\mathrm{CO}_{2}$ diffusion properties compared to the low and moderately loaded amine adsorbents. The modeling results were not associated with heat effects and gave accurate predictions of the breakthrough shape for the high loading aminosilica material.

Gomez et al. developed a one-dimensional (1D) adsorption breakthrough model using COMSOL Multiphysics for binary mixture $\mathrm{CO}_{2} / \mathrm{CH}_{4}$ to validate the experimental data for capturing $\mathrm{CO}_{2}$ by Metal Organic Framework (MOF) material, MOF-MIL-53(Al). ${ }^{14)}$ They took into account the effect of total and bed porosities. They validated the proposed model by simulating the breakthrough of $\mathrm{CO}_{2} / \mathrm{H}_{2}$ mixture in a column of activated carbon and compared the results with the experimental data from literature by Casas et al. ${ }^{15)}$ The results showed a good agreement between developed model and experimental data. Then the model was studied for a binary mixture of $\mathrm{CO}_{2} / \mathrm{CH}_{4}$ through MOF-MIL-53 at different operating parameters; adsorbent particle size, inlet pressure, gas flow rate and feed composition. Previously Casas et al. used the same developed model for simulating $\mathrm{CO}_{2}$ capturing using activated carbon to simulate experimental data for adsorption $\mathrm{CO}_{2}$ by UiO67/MCM-41 hybrid type of MOF. ${ }^{16)}$ Although the mass balance equation applied in the suggested mathematical model is usually applied for solutes and adsorbates with low concentrations (lower than $10 \mathrm{vol} \%$ ), the model provided good results at pressures 5, 15 and 25 bar for wide $\mathrm{CO}_{2}$ molar composition ranges, 25\%, 50\% and 75\%. Both total and bed porosities were considered in the models proposed by Casas et al. ${ }^{16)}$ and Gomez et al. ${ }^{14)}$ Mansour et al. model described $\mathrm{CO}_{2}$ adsorption and desorption from a stream representing flue gas $\left(15 \% \mathrm{CO}_{2}\right.$ and $85 \% \mathrm{~N}_{2}$ ) through a fixed bed where Mg-MOF-74 was used as sorbent. ${ }^{17)}$ The four-steps process was considered: pressurization, feed, blow down and purge.

In almost all published models, only axial direction was considered for mass and heat transfer studying. Lei et al. studied two dimensional (2D) model for the adsorption and desorption of $\mathrm{CO}_{2}$ to show the mass and heat balance in both axial and radial directions of the bed, where bed porosity was only involved in the mathematical modeling. ${ }^{18)}$ They established and solved a model for capturing $\mathrm{CO}_{2}$ from a gas mixture of $\mathrm{CO}_{2}$ and $\mathrm{N}_{2}$ by zeolite 5A using COMSOL Multiphysics software, while the experimental data to validate model were collected from literature. Aquino et al. studied adsorption of $\mathrm{CO}_{2}$ from binary mixture of $\mathrm{CO}_{2}$ and $\mathrm{N}_{2}$ by tuff, a natural type of zeolite, through a packed bed using three dimensional model (3D) Model using ANSYS FLUENT software. ${ }^{19}$ ) The mixed species transport and the $k$ - $\varepsilon$ turbulence model were applied to describe the binary species mixing and transport processes in turbulent regime. Also, the binary mixture was considered to be compressible ideal gas, while the mixture's diffusivities were calculated by multi component law. The modeling results were reported to provide remarkable agreement between data and simulation cases, which considered only the bed void fraction. Coker et al. developed several models, 2D and $3 \mathrm{D}$, to report the effect of radial effects for the combined water desiccant and carbon dioxide sorbent subsystems to describe removal of $\mathrm{CO}_{2}$ and water from air flow using four sorbents beds where bed porosity is only handled. ${ }^{20}$ ) The model included description for both adsorption and desorption systems. A 1D model was suggested to be an accurate one as air flowed uniformly through beds' channels.

The purpose of this study is to develop 1D models for $\mathrm{CO}_{2}$ adsorption using different capture materials at various operating conditions and feed streams. As shown above, the pervious CFD published reports were limited to CFD models for macropores without taking the mass transfer inside the micropores. On the other hand, the biporous models reported in the literature used specially developed solution implementation. What is unique in our work is that it is using one of CFD commercial software that has a built-in feature that can describe the multiscale mass transfer in the macro- and micro-pores. This feature has not been used before to simulate the $\mathrm{CO} 2$ capturing process. With this modeling approach, complicated modeling can be attempted, which make use of the strong software features such as solution methods, post processing, optimization, etc. The only published work that used multi-scale bi-porosity CFD modeling approach 
to describe adsorption and related mass transfer in mesopores and micropores was related to the adsorptive treatment of drinking water, in which a 3D model was developed for adsorption by superfine powered activated carbon. ${ }^{21)}$ This study discusses the results of the use of CFD with multi-scale biporous mass transfer feature to investigate the effects of macropores and micropores of different capture materials on the $\mathrm{CO}_{2}$ mass transfer during adsorption process.

The remainder of the paper is organized as follows in Section 2, the mathematical model is introduced while Section 3 shows how the proposed model is implemented and the selected cases for testing the suggested model. The comparison between simulated breakthrough curves by the developed model and experimental data from literature is shown in Section 4.

\section{Mathematical Modelling}

\subsection{Governing equations}

The objective of this study is to model the mass transfer of $\mathrm{CO}_{2}$ adsorption process in a packed bed column by different sorbents. The model showed the mass transfer in the bulk fluid within the column and in the porous solid adsorbent pellet, macropores and micropores. The model has developed using the following assumptions:

- The gas phase was considered as an ideal gas.

- The axial dispersed plug flow was adopted, while the concentration gradient in radial direction was neglected.

- Mass transfer between the fluid and the sorbent surface was considered and described by a linear driving force model, while the mass transfer within micropores was described by the pore diffusion model

- The fixed bed was treated as isothermal, except in one of the cases in which a comparison between isothermal and non-isothermal results was made.

- Only the adsorption of $\mathrm{CO}_{2}$ was considered in all models.

- For the sorbents' pellet, the mobile fluid phase in the voids of pellet and the pellet solid were assumed to be locally in thermal equilibrium.

- The sorbent pellets were considered to be homogenous spheres with uniform size.

\subsection{Mass balance equations}

The transfer of material in the adsorption unit can be investigated at two different scales: the scale of mass transfer between the adsorbent particles (bulk) and the scale of mass transfer inside the adsorbent particles. Typically, the size of particles ranges from 500 to 1000 $\mu \mathrm{m}$. The bulk porosity of the bed typically differs from the porosity in the particles. Thus, mass transfer occurs at two different scales and the bed can be studied with two different porosities.

In the bulk gas, the rate of $\mathrm{CO} 2$ concentration flowing along the fixed bed at any axial position can be given by the following Equation (1) ${ }^{22)}$ :

$$
\begin{aligned}
\varepsilon_{b} \frac{\partial c_{A}}{\partial t}=\varepsilon_{b} D_{L} & \frac{\partial^{2} c_{A}}{\partial z^{2}}-\varepsilon_{b} u_{g} \frac{\partial c_{A}}{\partial z} \\
& +\left(1-\varepsilon_{b}\right) k_{f} \frac{3}{r_{p}}\left(c_{A}-\left.c_{p}\right|_{r=r_{p}}\right)
\end{aligned}
$$

The right-hand side terms of the above equation represent the axial dispersion within the column, the convective transfer of $\mathrm{CO}_{2}$, and the transfer of $\mathrm{CO}_{2}$ from the bulk gas fluid through macropores to the sorbent particles, respectively.

On the other hand, the pore diffusion model predicts the mass transfer within the micropores of sorbent pellet. Equation (2) shows that $\mathrm{CO}_{2}$ transferred from bulk fluid to the sorbent surface diffuses along pellet pores because of concentration gradient. It is assumed that the mechanism of adsorption of $\mathrm{CO}_{2}$ onto the sorbent surface is instantaneous within comparison to other mass transfer mechanisms ${ }^{22-23)}$

$\varepsilon_{p} \frac{\partial c_{p}}{\partial t}=D_{m}\left(\frac{1}{r^{2}} \frac{\partial}{\partial r}\left(r^{2} \frac{\partial c_{p}}{\partial r}\right)\right)-\left(1-\varepsilon_{p}\right) \frac{\partial q}{\partial t}$

The Linear Driving Force Model (LDF) has been applied in this work to represent the rate adsorption of $\mathrm{CO}_{2}$ in the micropores of solid pellet and intraparticle mass transfer resistance. The LDF is given as shown in Equation $(3)^{24)}$ :

$\frac{\partial q_{i}}{\partial t}=k_{s}\left(q_{e}-q_{i}\right)$

The effective mass transfer coefficient $k_{s}$ can be a function of pressure, temperature and/or $\mathrm{CO}_{2}$ concentration in adsorbed phase ${ }^{12}$ ).

\subsubsection{Mass Transfer Correlations}

The average external mass transfer coefficient between the gas bulk stream flowing through the fixed bed and the sorbent pellet was calculated using the following Equation $(4)^{25}$ :

$k_{f}=\frac{u_{g}}{\varepsilon_{b} S c^{2 / 3}}\left(\frac{0.765}{R e^{0.82}}+\frac{0.365}{R e^{0.386}}\right)$

The molecular diffusion of $\mathrm{CO}_{2}$ in the gas stream was calculated using the Chapman-Enskog Equation(5) ${ }^{26)}$ :

$D_{m}=\frac{0.0018583 \sqrt{T^{3}\left(\frac{1}{M_{A}}+\frac{1}{M_{B}}\right)}}{P \sigma_{A B}^{2} \Omega_{A B}}$

The axial dispersion coefficient, $D_{L}$, was estimated using Edwards-Richardson correlation as shown in Equation (6) ${ }^{27)}$ :

$D_{L}=0.73 D_{m}+\frac{0.5 d_{p} u_{g}}{1+9.49 \times D_{m} / d_{p} u_{g}}$

\subsubsection{Boundary and Initial Conditions for Mass Transfer Equations}

To solve mass balance Equation (1), two boundary conditions are required. The boundary conditions for dispersed plug flow system were assumed based on 
Danckwert's boundary conditions as Equations (7) and (8). ${ }^{28)}$ The concentration of $\mathrm{CO}_{2}$ at the fixed bed entrance is constant and at the column exit the diffusive flux was assumed to be zero:

$\left.D_{L} \frac{\partial c_{A}}{\partial z}\right|_{z=0}=\left.u\right|_{z=0}\left(\left.c_{i}\right|_{z=0^{-}}-\left.c_{i}\right|_{z=0}\right)$

$\left.\frac{\partial c_{i}}{\partial z}\right|_{z=L}=0$

For solving mass balance Equation (2), additional two boundary conditions are required. For both the center and the surface of the pellet, the rate of diffusion within the pellet equals to the convective mass flux of bulk fluid, as shown in Equations (9) and (10) ${ }^{29)}$ :

$\left.\frac{\partial c_{p}}{\partial r}\right|_{r=0}=0, t \geq 0$

$-D_{m} \frac{\partial c_{p}}{\partial r}=k_{f}\left(c_{A}-\left.c_{p}\right|_{r=r_{p}}\right) t \geq 0$

The fixed bed column was assumed to not have carbon dioxide at any point in the column at initial conditions. This assumption is matched with different literature experiments that were applied to regenerate the bed for remove any traces of $\mathrm{CO}_{2}^{22)}$. The initial conditions can be described as following Equation (11):

$c_{A}=0, c_{p}=0, q=0 \quad t=0, \forall(r, z)$

The above initial condition was applied for both bulk fluid concentration and $\mathrm{CO}_{2}$ concentration in the pellet.

\subsection{Heat Transfer}

This study includes three different adsorption cases where isothermal models are assumed. Case 2 (shown in details in Section 3.1) was simulated in both isothermal and adiabatic mode to show how the temperature rise during adsorption process may effect on the breakthrough curve. The energy balance equation for the column included solid and fluid phases can be written as the following Equation (12) ${ }^{16)}$ :

$$
\begin{gathered}
\left(\varepsilon_{t} C_{g}+\rho_{b} C_{s}+\rho_{b} C_{a d s}\right) \frac{\partial T_{g}}{\partial t}-\varepsilon_{t} \frac{\partial P}{\partial t}+u C_{g} \frac{\partial\left(T_{g}\right)}{\partial z} \\
-\rho_{P} \sum_{i=1}^{n}\left(-\Delta H_{i}\right) \frac{\partial q_{i}}{\partial t}+\frac{4 h_{L}}{d b\left(T_{g}-T_{W}\right)}=\frac{\partial}{\partial z}\left(K_{L} \frac{\partial T_{g}}{\partial z}\right)
\end{gathered}
$$

While the energy balance around the wall can be written as the following Equation (13) ${ }^{16)}$

$$
\begin{aligned}
& \frac{\partial T_{w}}{\partial t}=\frac{2 \pi}{C_{W}\left(r_{o}{ }^{2}-r_{i}{ }^{2}\right)}\left[h_{L} r_{i}\left(T_{g}-T_{W}\right)\right. \\
& \left.-h_{w} r_{o}\left(T_{W}-T_{a m t}\right)\right] \\
& +\frac{1}{C_{W}} \frac{\partial}{\partial z}\left(K_{W} \frac{\partial T_{W}}{\partial z}\right)
\end{aligned}
$$

The heat capacities for both the fluid and adsorbed phase are defined as the following Equations (14) and (15):

$$
\begin{gathered}
C_{g}==\sum_{i=1}^{n} c_{i} C_{p, i}^{\text {mole }} \\
C_{\text {ads }}==\sum_{i=1}^{n} q_{i} C_{g, i}^{\text {mole }}
\end{gathered}
$$

The lumped heat transfer coefficient for both gas and solid phases $h_{L}$ is a function in Renolds number, the diameter of the column and the pellet diameter and was calculated using Leva's correlation. ${ }^{16)}$

$$
N u \equiv \frac{h_{L} R_{i}}{k_{L}}=\beta_{1} R e^{\beta_{2}}\left(-6 d_{p} / 2 r_{i}\right)
$$

\subsubsection{Boundary and Initial Conditions for Heat Transfer Equations}

The initial condition applied for heat balance Equations (12) and (13) is shown in the following Equation (17):

$T_{g}=T_{W}=T_{a m t}$

While the boundary conditions were written as the following Equation (18):

$\frac{\partial T_{g}}{\partial z}=0, z=0, L ; t \geq 0$

\section{$2.4 \quad$ Isotherms}

The equilibrium adsorption capacities of a capture materials can be calculated from isotherms that were fitted the experimental data. For the selected cases that is discussed in Section 2.4, Langmuir isotherm model as shown in the Equation (19) was fitted the experimental data:

$q_{e}=\frac{\mathrm{q}_{\max } K_{i} P_{i}}{1+K_{i} P_{i}}$

The temperature dependence parameter $K_{i}$ is calculated as shown in Equation (20) by using the van't Hoff equation $^{30)}$ :

$K_{i}=K_{i 0} \exp \left(\frac{-\Delta H_{a d s}}{R T}\right)$

\subsection{Pressure Drop}

The pressure distribution through the packed bed was described by the Ergun Equation (21) ${ }^{31)}$ :

$\frac{\partial P}{\partial z}=-K_{D} u_{g}-K_{v} u_{g}{ }^{2}$

where $K_{D}$ and $K_{V}$, described in Equations (22) and (23), are parameters representing the viscous and kinetic pressure loss terms respectively.

$$
\begin{aligned}
& K_{D}=150 \frac{\mu_{g}\left[\lambda_{s}\left(1-\varepsilon_{b}\right)\right]^{2}}{d_{p}^{2} \varepsilon_{b}^{3}} \\
& K_{v}=1.75 \frac{\lambda_{s}\left(1-\varepsilon_{b}\right) \rho_{g}}{d_{p} \varepsilon_{b}^{3}}
\end{aligned}
$$

\section{Implementation}

In this work, all equations shown in the above section were solved by using COMSOL. The transport of diluted 
species was selected to be the main physics package that describes mass balance in the bulk flow as shown in Equation (1). While the reactive-pellet feature was added to simulate the adsorption in micropores of sorbents pellets via the mass balance (Equation 2). The LDF equation was written as an ordinary differential equation where the rate of change of $q$ can be added as a reaction term in the reactive pellet equation to account the rate of $\mathrm{CO}_{2}$ adsorption in the micropores of sorbent's pellet. The energy balance equations for case 2 were written as partial differential equations.

\subsection{Selected Cases}

Different experimental data were selected to test the developed model using COMSOL. The following Table (1) and Table (2) summarize the design parameters for selected cases, while Table (3) shows the design parameters used to simulate heat balance equations for case (2)

Table 1: Selected cases for modeling

\begin{tabular}{|l|l|l|}
\hline Case Parameter & Case ${ }^{12)}$ & Case ${ }^{16)}$ \\
\hline Material & Hydrotalcite & $\begin{array}{l}\text { UiO-67/MCM-41 } \\
\text { hybrid }\end{array}$ \\
\hline Feed stream & $\mathrm{CO}_{2}, \mathrm{~N}_{2}$ & $\mathrm{CO} 2, \mathrm{H}_{2}$ \\
\hline $\mathrm{db}, \mathrm{m}$ & 0.0384 & 0.025 \\
\hline$r_{p}, \mu \mathrm{m}$ & $\begin{array}{l}800^{*} \\
250^{* *}\end{array}$ & 1000 \\
\hline $\mathrm{L}, \mathrm{m}$ & 0.318 & 1.2 \\
\hline$\varepsilon_{b}$ & 0.48 & 0.42 \\
\hline$\varepsilon_{p}$ & 0.24 & 0.37 \\
\hline$\rho_{b}, \mathrm{~kg} / \mathrm{m}^{3}$ & 811 & 320 \\
\hline$\rho_{P} \mathrm{~kg} / \mathrm{m}^{3}$ & 1563 & 557 \\
\hline$\rho_{S}, \mathrm{~kg} / \mathrm{m}^{3}$ & 2056.5 & 1570 \\
\hline$\mu_{g}, \mathrm{~Pa} . \mathrm{s}$ & $3 \times 10^{-5}$ & $1.46 \times 10^{-5}$ \\
\hline
\end{tabular}

* cylindrical pellets

** Spherical pellets

For cylindrical pellets in case 1 , the mean diameter of pellets is determined using below Equation (24) to represent the cylindrical pellet in the spherical coordinates

$r_{p}=3 \frac{V_{p e}}{A_{p e}}$

Table 2: Selected cases for modeling

\begin{tabular}{|l|l|}
\hline Case Parameter & Case ${ }^{25)}$ \\
\hline Material & BPL Activated Carbon \\
\hline Feed stream & $\mathrm{CO}_{2}$ \\
\hline $\mathrm{db}, \mathrm{m}$ & 0.01 \\
\hline$r_{p}, \mu \mathrm{m}$ & 450 \\
\hline $\mathrm{L}, \mathrm{m}$ & 0.13 \\
\hline$\varepsilon_{b}$ & 0.5 \\
\hline$\varepsilon_{p}$ & 0.312 \\
\hline$\rho_{b}, \mathrm{~kg} / \mathrm{m}^{3}$ & 466.35 \\
\hline$\rho_{P} \mathrm{~kg} / \mathrm{m}^{3}$ & 932.7 \\
\hline$\rho_{S}, \mathrm{~kg} / \mathrm{m}^{3}$ & ---- \\
\hline$\mu_{g}, \mathrm{~Pa} . \mathrm{s}$ & $1.65 \times 10^{-5}$ \\
\hline
\end{tabular}

Each model was tested at different operating conditions to show the stability of developed model at different temperatures, feed composition and pressure runs as shown in Table (4).

Table 3: Required parameters for solving energy balance equations (case 2)

\begin{tabular}{|l|l|}
\hline Case Parameter & Case ${ }^{16)}$ \\
\hline$C_{W}, \mathrm{~J} /\left(\mathrm{K} \mathrm{m}^{3}\right)$ & $4 \times 10^{6}$ \\
\hline$C_{S}, \mathrm{~J} /(\mathrm{K} \mathrm{kg})$ & 1250 \\
\hline$-\Delta H_{\mathrm{CO}_{2}}, \mathrm{~J} / \mathrm{mole}$ & 19000 \\
\hline$-\Delta H_{\mathrm{H}_{2}}, \mathrm{~J} / \mathrm{mole}$ & 9000 \\
\hline$K_{L}, \mathrm{~J} /(\mathrm{m} \mathrm{s} \mathrm{K})$ & 0.35 \\
\hline$K_{T}, \mathrm{~J} /(\mathrm{m} \mathrm{s} \mathrm{K})$ & 16 \\
\hline$K_{W}, \mathrm{~J} /(\mathrm{m} \mathrm{s} \mathrm{K})$ & 16 \\
\hline$\beta_{1}$ & 19 \\
\hline$\beta_{2}$ & 0.04 \\
\hline
\end{tabular}

Table 4 Operating conditions for selected runs

\begin{tabular}{|c|c|c|c|c|}
\hline $\begin{array}{c}\text { Case } \\
\text { Input }\end{array}$ & $y_{\mathrm{CO}_{2}}$ & $\mathrm{P}_{\text {feed }}$, bar & $\mathrm{T}_{\text {feed }}, \mathrm{K}$ & $\begin{array}{c}\mathrm{Q}_{\text {feed }} \\
\mathrm{cm}^{3} / \mathrm{s}\end{array}$ \\
\hline \multicolumn{5}{|c|}{ Case 1} \\
\hline Run 1 & 0.0261 & 4.68 & 673 & $4.62^{* *}$ \\
\hline Run 2 & 0.0162 & 18.7 & 673 & $4.63^{* *}$ \\
\hline Run 3 & 0.1993 & 1.14 & 673 & $4.63^{* *}$ \\
\hline \multicolumn{5}{|c|}{ Case 2 } \\
\hline Run 1 & 0.25 & 5 & 298 & 10 \\
\hline Run 2 & 0.25 & 15 & 298 & 10 \\
\hline Run 3 & 0.25 & 25 & 298 & 10 \\
\hline \multicolumn{5}{|c|}{ Case 3 } \\
\hline Run 1 & 0.42 & 3 & 338 & 1.5 \\
\hline Run 2 & 0.62 & 3 & 338 & 1.5 \\
\hline
\end{tabular}

* Cylindrical pellets

**SLPM

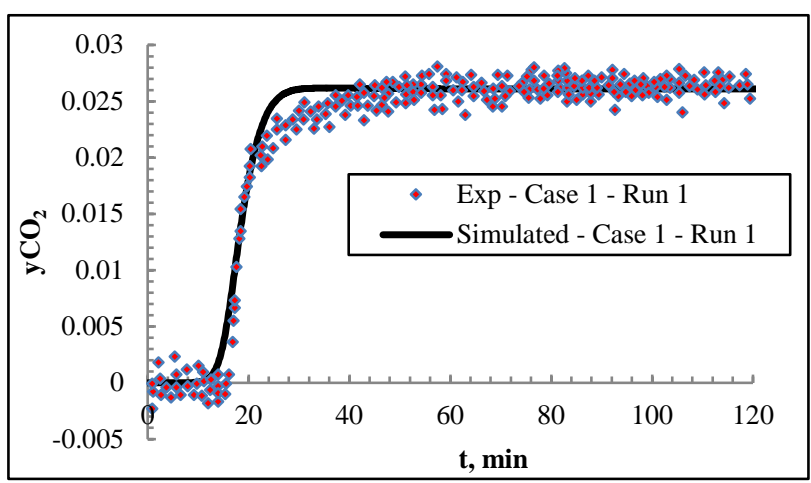

Figure 1: Simulated breakthrough curve of $\mathrm{CO}_{2}$ for case1run 1 . Solid line for model and dots for experimental data (cylindrical pellet).

\section{Results and discussion}

The mathematical model has been used to predict the breakthrough curves of $\mathrm{CO}_{2}$ at selected conditions and runs shown in Tables (1), (2) and (3). The breakthrough curves of $\mathrm{CO}_{2}$ are shown in Figure 1-3 for the case 1 at 
different operating runs. For case 1, the use of LDF resulted in good fitting for all cases for the same value for mass transfer coefficient, $\mathrm{k}_{\mathrm{s}}, 0.01 \mathrm{~s}^{-1}$.

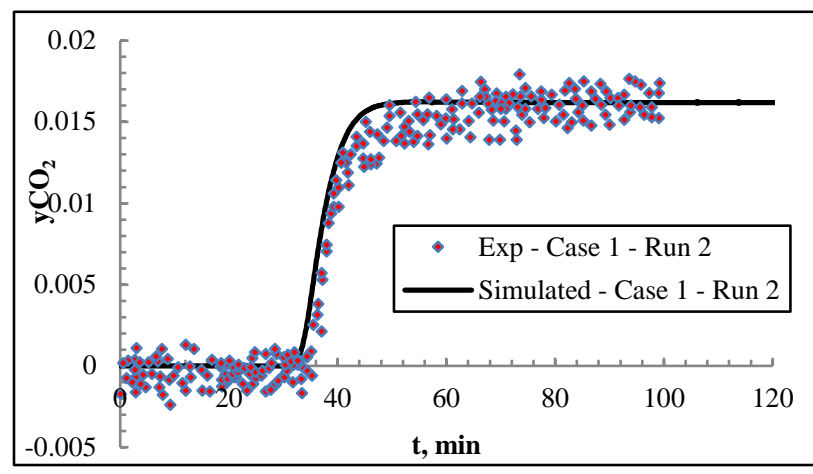

Figure 2:Simulated breakthrough curve of $\mathrm{CO}_{2}$ for case 1 - run 2. Solid line for model and dots for experimental data (cylindrical pellet).

Figure (4) shows the adsorbed amount of $\mathrm{CO}_{2}$ by solid sorbent for case 1 at different runs. The highest value was accounted for run 2 at 17.26 bar. This indicates the effect of the feed pressure for $\mathrm{CO}_{2}$ adsorption although it has a less effect on the mass transfer coefficient.

For case 2 as shown in Figure (5), the model over predicts. This model is solved in both isothermal and adiabatic modes to indicate if the significant deviation between experimental data and simulated model is a result from neglecting heat of adsorption or from effect of pellets' micropores. Figure (6) shows no significant change in the breakthrough curves of case 2, for run 2 and run 3 , between two modes. This means that the deviation is a result of over estimation for adsorption occurred in micropores of the pellet. It can be indicated on the more time required for bed saturation compared with experimental data although it predicted the first adsorption zone with a good agreement with the experimental data for all runs. Thus, the adsorption of $\mathrm{CO}_{2}$ by UiO67/MCM-41, a hybrid type of MOF, does not fully depend on the intraparticle transport mechanism and surface diffusion is dominated. The longer the breakthrough time the higher dynamic adsorption capacity for sorbent. While a fast increase in the breakthrough curve means less resistance in intraparticle mass transfer ${ }^{32)}$. The overestimation for the adsorption in micropores affects also on the temperature profile. Figure (7) shows a comparison between experimental temperature at location $110 \mathrm{~cm}$ of the bed and the simulated model.

In case 3, for both runs 1 and 2 are shown in Figure (8), the model provides a good fitting for pure $\mathrm{CO}_{2}$ capture based with helium using BPL activated carbon sorbent with a small deviation in the curve after the bed is saturated with $\mathrm{CO}_{2}$. This deviation may be due to small prediction for internal diffusion of adsorbate in the solid pellet in the saturation zone of the bed.

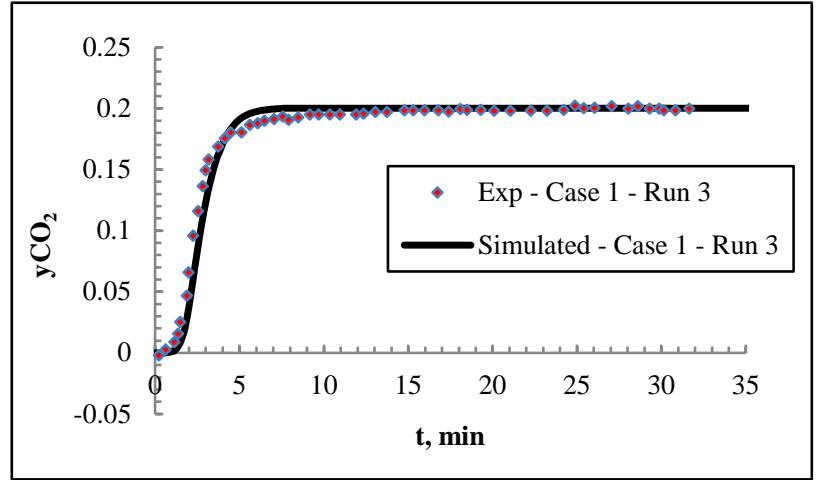

Figure 3:Simulated breakthrough curve of $\mathrm{CO}_{2}$ for case 1-run3. Solid line for model and dots for experimental data (spherical pellet)

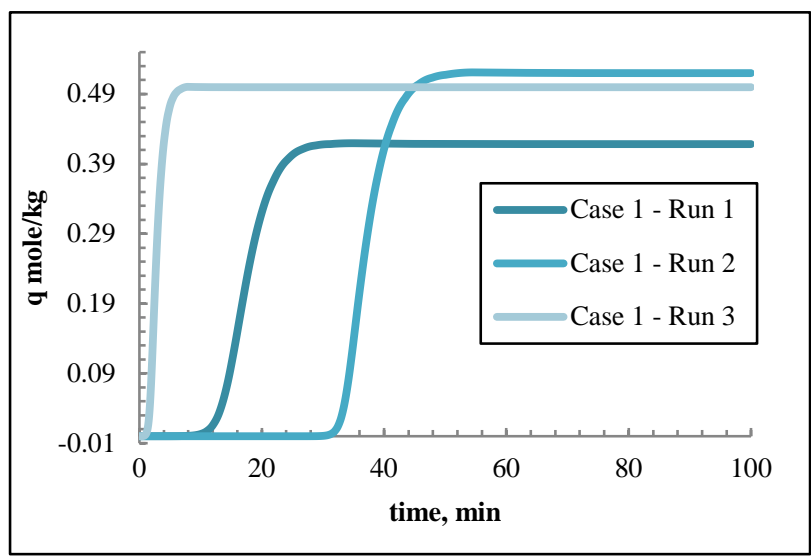

Figure 4: q curves for case 1 at different runs

The feed pressure mixture is observed to decrease the breakthrough time. The highest breakthrough time is recorded for run 1 at 5 bar while the lowest one is observed in run 3 at 25 bar. The same behavior was mentioned by Gomez et al. while applying experiments for adsorption $\mathrm{CO}_{2}$ from $\mathrm{CO}_{2} / \mathrm{CH}_{4}$ mixture stream by aluminum terephthalate MOF-MIL-53 (Al). ${ }^{14)}$

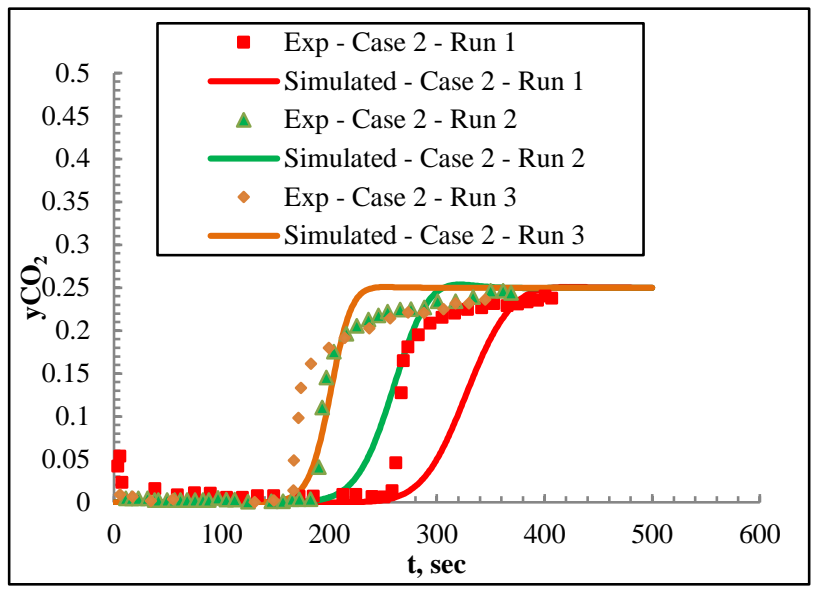

Figure 5: Simulated breakthrough curve of $\mathrm{CO}_{2}$ for case 2 - isothermal mode. Solid line for model and dots for experimental data 


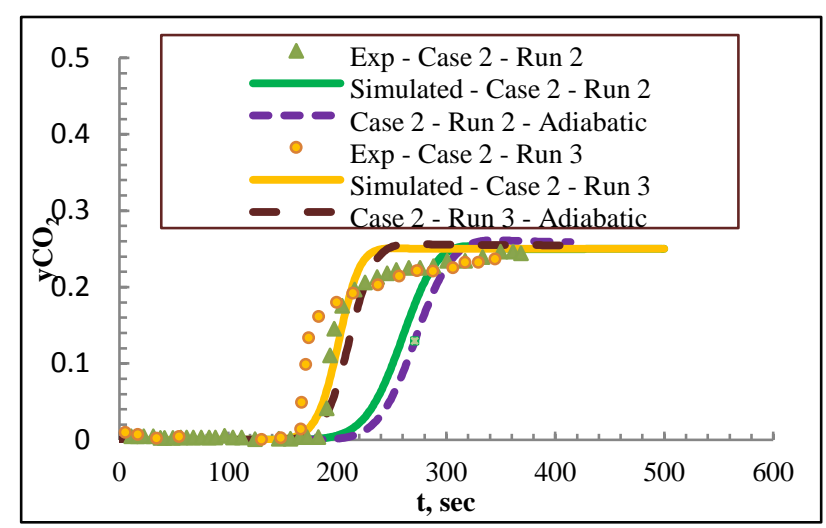

Figure 6: Comparison of simulated breakthrough curve of $\mathrm{CO}_{2}$ for case 2 (run 2 and run 3) in isothermal and adiabatic modes. Solid line for model and dots for experimental data.

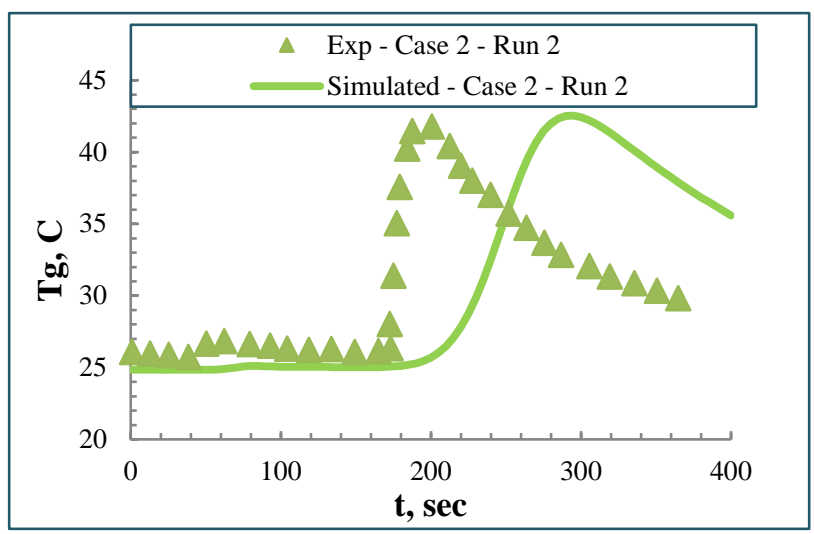

Figure 7: Comparison of simulated breakthrough curve of $\mathrm{CO}_{2}$ for case 2 (run 2) in adiabatic modes. Solid line for model and dots for experimental data.

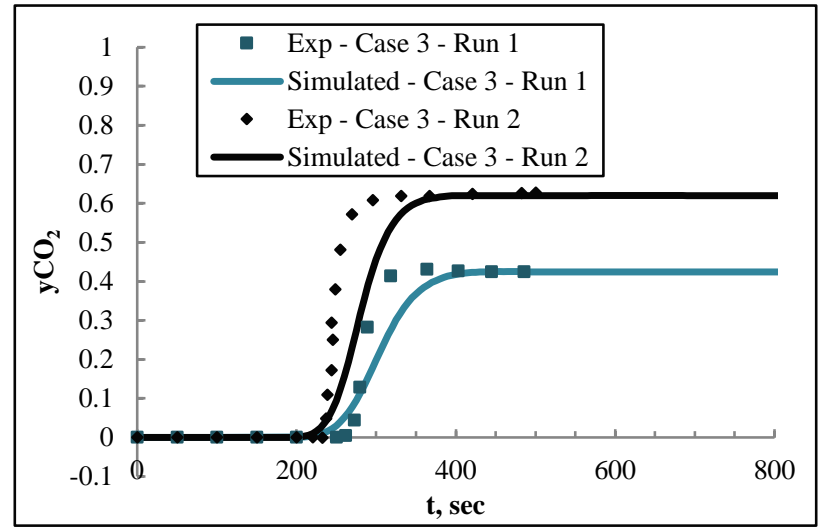

Figure 8: Simulated breakthrough curve of $\mathrm{CO}_{2}$ for case 3 - run 1 and run 2. Solid line for model and dots for experimental data

\section{Conclusions}

In this work, different experimental data from literature for capturing $\mathrm{CO}_{2}$ has been simulated to show mass transfer during the adsorption process in a fixed bed column. One dimensional models have been developed by solving the differential equations of described mathematical model using COMSOL Multiphysics software including reactive pellet feature to describe the mass transfer in mesopores and micropores of sorbent pellets. Good fits between simulated breakthrough curves and experimental data have been obtained for $\mathrm{CO}_{2}$ capturing using hydrotalcite while an over prediction for mass transfer in micropores has been obtained for the model describing $\mathrm{CO}_{2}$ capturing by UiO-67/MCM-41, a hybrid type of MOF. A good prediction was shown for modeling capture $\mathrm{CO}_{2}$ by BPL activated carbon sorbent. Thus, multi-scale modeling using COMSOL can provide a useful predictive tool for understanding, design and optimization of $\mathrm{CO}_{2}$ adsorption processes as separation techniques for the removal of $\mathrm{CO}_{2}$ from flue gases.

\section{Nomenclature}

$A_{p e} \quad$ pellet area $\left(\mathrm{m}^{2}\right)$

$c$ concentration of gas in the bulk phase $\left(\mathrm{mol} / \mathrm{m}^{3}\right)$

$C_{a d s} \quad$ heat capacity of the adsorbed phase ( $\mathrm{J} /(\mathrm{K} \mathrm{kg})$

$C_{g} \quad$ heat capacity of the gas $\left(\mathrm{J} /\left(\mathrm{K} \mathrm{m}^{3}\right)\right.$

$C_{g, i}^{\text {mole }} \quad$ Specific heat capacity of the gas for species i ( J/(K.mole))

$C_{s} \quad$ Heat capacity of the solid ( $\mathrm{J} /\left(\mathrm{K} \mathrm{m}^{3}\right)$

$C_{w} \quad$ Lumped heat capacity of the wall $\left(\mathrm{J} /\left(\mathrm{K} \mathrm{m}^{3}\right)\right.$

$c_{p} \quad$ concentration in pellet $\left(\mathrm{mol} \mathrm{m}^{-3}\right)$

$D_{e} \quad$ effective diffusivity $\left(\mathrm{m}^{2} / \mathrm{s}\right)$

$D_{L} \quad$ axial dispersion coefficient $\left(\mathrm{m}^{2} / \mathrm{s}\right)$

$D_{M} \quad$ molecular diffusion coefficient of $\mathrm{CO}_{2}\left(\mathrm{~m}^{2} / \mathrm{s}\right)$

$K_{i} \quad$ Langmuir model constant for component i (1/bar)

$K_{i_{0}} \quad$ Langmuir model constant for component i (1/bar)

$k_{f} \quad$ external film mass transfer coefficient (m/s)

$-\Delta H_{i} \quad$ heat of adsorption of species i, J/mole

$h_{L} \quad$ heat transfer coefficient (lumping gas phase + wall $)\left(\mathrm{J} /\left(\mathrm{m}^{2} \mathrm{~s} \mathrm{~K}\right)\right)$

$h_{w} \quad$ heat transfer coefficient (lumping wall + heat of adsorption) ( $\mathrm{J} /\left(\mathrm{m}^{2} \mathrm{~s} \mathrm{~K}\right)$ )

$K_{L} \quad$ thermal conductivity in the fluid phase $(\mathrm{J} /(\mathrm{m}$ s K))

$K_{T} \quad$ lumped thermal conductivity (fluid and solid ) (J/(m s K))

$K_{w} \quad$ thermal conductivity in the wall of the column (J/(m s K))

$\mathrm{L} \quad$ bed length $(\mathrm{m})$

$P \quad$ total pressure (bar)

$P_{i} \quad$ partial pressure of component i (bar)

Q Volumetric flow rate $\left(\mathrm{m}^{3} / \mathrm{s}\right)$

$q \quad$ adsorbed phase concentration on the sorbent solid (mole/kg)

$q_{e} \quad$ equilibrium solid phase concentration (mole/kg) 


$\begin{array}{ll}\mathrm{R} & \text { Universal gas constant ( J/mole.K) } \\ \mathrm{Re} & \text { Reynolds number (dimensionless) } \\ r_{i} & \text { inner column radius (m) } \\ r_{o} & \text { outer column radius (m) } \\ \mathrm{Sc} & \text { Schmidt number (dimensionless) } \\ \mathrm{Sh} & \text { Sherwood number (dimensionless) } \\ T & \text { temperature (K) } \\ T_{a m t} & \text { ambient temperature (K) } \\ T_{a} & \text { gas temperature }(\mathrm{K}) \\ T_{w} & \text { wall temperature }(\mathrm{K}) \\ t & \text { time } \\ u & \text { velocity (m/s) } \\ V_{p e} & \left.\text { pellet volume (m }{ }^{3}\right) \\ y & \text { mole fraction } \\ \mathrm{z} & \text { axial coordinate, } \mathrm{m}\end{array}$

\section{Abbreviations}

$\begin{array}{cl}\mathrm{CCS} & \text { carbon dioxide capture and storage } \\ \mathrm{CFD} & \text { Computational Fluid Dynamics } \\ \mathrm{CO}_{2} & \text { carbon dioxide } \\ \mathrm{CH}_{4} & \text { methane } \\ \text { Exp } & \text { experimental } \\ \mathrm{GHG} & \text { greenhouse gases } \\ \mathrm{H}_{2} & \text { hydrogen } \\ \text { IGCC } & \text { integrated gasification combined cycle } \\ \text { IPCC } & \text { Intergovernmental Panel on Climate Change } \\ \text { LDF } & \text { Linear Driving Force } \\ \text { MOF } & \text { metal frame work } \\ \mathrm{N}_{2} & \text { nitrogen } \\ \text { SLPM } & \text { standard liter per minute } \\ \text { vol } & \text { volume }\end{array}$

\section{Greek Letters}

$\begin{array}{cl}\varepsilon_{b} & \text { bed void fraction } \\ \varepsilon_{p} & \text { sorbent pellet porosity } \\ \mu & \text { dynamic viscosity }(\mathrm{Pa} . \mathrm{s}) \\ \rho & \text { fluid phase density }\left(\mathrm{kg} / \mathrm{m}^{3}\right) \\ \rho_{b} & \text { bed density }\left(\mathrm{kg} / \mathrm{m}^{3}\right) \\ \rho_{P} & \text { pellet particle density }\left(\mathrm{kg} / \mathrm{m}^{3}\right) \\ \rho_{S} & \text { pellet solid density }\left(\mathrm{kg} / \mathrm{m}^{3}\right) \\ \beta & \text { Leva's correlation parameters }\end{array}$

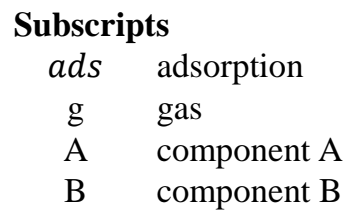

\section{References}

1) A. Wagner, B. Steen, G. Johansson, E. Zanghellini, P. Jacobsson, and P. Johansson, Int. J. Spectrosc., 2013, 1-8, (2013).

2) D. Li, H. Furukawa, H. Deng, C. Liu, O. M. Yaghi, and D. S. Eisenberg, Proc. Natl. Acad. Sci., 111, 191-196, (2014)

3) C. A. Grande,ISRN Chemical Engineering,
2012,(2012).

4) J. G. J. Olivier, K. M. Schure, and J. A. H. W. Peters, "Trends in Global $\mathrm{CO}_{2}$ and Total Greenhouse Gas Emissions: Summary of the 2017 Report,(2017).

5) S. Notosiswoyo and I. Iskandar, J. of Novel Carbon Resource Sciences, 4, 17-20, (2011)

6) D. M. D’Alessandro and T. McDonald,Pure Appl. Chem., 83, 57-66,(2010).

7) IEA. Greenhouse Gas emissions from Major Industrail Sources III- Iron andSteel Report . IEA greenhouse gas $R$ \&amp; D Programme , PH3/30, (2000).

8) European Environmental Agency. Greenhouse Gas Emission Trends and Projections in Europa, tracking progress towards Kyoto targets. 2008. 5/2008.

9) R. Serna-guerrero and A. Sayari, Chem. Eng. J., 161, 182-190, (2010).

10) M. S. Shafeeyan, W. Mohd, A. Wan, and A. Shamiri,Energy Fuels, 29, 6565-6577, (2015).

11) A. Qasim, M. Z. Abdullah, L. K. Keong, and S. Yusup,9, 163-169,(2014).

12) Y. Ding and E. Alpay, Chemical Engineering Science,55, 3461-3474, (2000).

13) P. Bollini, N. A. Brunelli, S. A. Didas, and C. W. Jones, “Ind. Eng. Chem. Res., 51 (46), 2012

14) L. F. Gomez, R. Zacharia, P. Bénard, and R. Chahine, Journal of Nanomaterials,2015, 2015.

15) N. Casas, J. Schell, and R. Pini,Adsroption, 18,143161, 2012.

16) N. Casas, J. Schell, R. Blom, and M. Mazzotti, Sep. Purif. Technol., 112, 34-48, (2013).

17) R. Ben-Mansour, M. Basha, and N. A. A. Qasem, Comput. Chem. Eng., 99, 255-270, (2017).

18) M. Lei, C. Vallieres, G. Grevillot, and M. A. Lati, Ind. Eng. Chem. Res., 52 ,(2013).

19) A. Aquino, E. Bonamente, C. Buratti, F. Cotana, V. Paolini, and F. Petracchini, Energy Procedia, 101, 392-399, (2016).

20) R. F. Coker, J. Knox, G. Schunk, and C. Gomez, 45th Int. Conf. Environ. Syst., (2015).

21) E. Partlan, "Superfine Powdered Activated Carbon ( S-PAC ) Coupled with Microfiltration for the Removal of Trace Organics in Drinking Water Treatment," 2017.

22) V. P. Mulgundmath, R. A. Jones, F. H. Tezel, and J. Thibault, Sep. Purif. Technol.85,17-27, (2012).

23) R. T. Doong, S J; Yang, AIChE,11, 1829-1842, (1985).

24) E. Glueckauf and J. I. Coates,J. Chem. Soc., 13151321, (1947).

25) P. Brea, J. A. Delgado, V. I. Águeda, and M. A. , Sep. Purif. Technol.,179,61-71, (2017).

26) S. Chapman and T. G. Cowling, The mathematical theory of non-uniform gases: an account of the kinetic theory of viscosity, thermal conduction and diffusion in gases. Cambridge University press, (1970). 
27) M. F. Edwards and J. F. Richardson,J.Chem. Eng. ,48, 466-467, (1970).

28) M. S. Shafeeyan, W. Mohd, A. Wan, and A. Shamiri, Chem. Eng. Res. Des., 92,(2013).

29) J. F. Wehner and R. H. Wilhelm, Chem. Eng. Sci,6, 89-93, (1956).

30) J. H. Van't Hoff, Studien zur chemischen Dynamik. F. Muller, (1896).

31) S. Ergun, "Fluid flow through packed columns," Chem. Eng. Prog., 48,89-94, (1952).

32) Kosuge, K.; Kubo, S.; Kikukawa, N.; Takemori, M. Effect of Pore Structure in Mesoporous Silicas on VOC Dynamic Adsorption / Desorption Performance, Langmuir,23, 3095-3102, (2007) 